\title{
Example of an Investigation of an "Emergent" Phenomenon in Addiction Vigilance: the Case of Methylphenidate
}

\author{
Joëlle Micallef ${ }^{1}$, Elisabeth Frauger ${ }^{1}$, Aurore Palmaro ${ }^{2}$, Quentin Boucherie ${ }^{1}$ and Maryse Lapeyre Mestre ${ }^{2}$ \\ 1 CEIP-Addictovigilance Paca Corse, Service de Pharmacologie Clinique \& Pharmacovigilance, Aix Marseille Université, \\ Institut de Neurosciences Timone, CNRS 7289, Marseille, France \\ 2 CEIP-Addictovigilance de Toulouse, Service de Pharmacologie Médicale et Clinique, Centre Hospitalier Universitaire, \\ Faculté de Médecine, Université de Toulouse III, Inserm, UMR1027, Toulouse, France
}

Texte received August 26 $6^{\text {th }}, 2014$; accepted September $2^{\text {nd }}, 2014$

\section{Keywords:}

methylphenidate; abuse; use of drug; pharmacoepidemiology; signal

\begin{abstract}
Abuse of and addiction to medication are a major public health issue which is evolving fast, in particular in countries like France, one of the largest consumers of medication in Europe. As a single source of information is not generally sufficient to measure a phenomenon as difficult to apprehend as medication-related addiction, as can be seen in the case of methylphenidate, it is essential to mobilise all the tools available, here surveillance programmes developed by the French CEIP Addiction vigilance network, such as suspicious prescriptions indicating possible abuse data (OSIAP) or observatory of illegal or misused psychoactive medications (OPPIDUM), as well as the health insurance databases, and health professional sentinel networks. The latest data available on methylphenidate abuse in France suggests a stabilisation of the phenomenon, which emerged in the Provence-Alpes-Côte-d'Azur (PACA) region in southern France. It also evidences its diffusion to other regions, so that the information needs to be widely relayed, and suggests that health professionals should exercise the greatest caution in the use of this substance, and should look for early signs of its misuse.
\end{abstract}

Abbreviations: see end of article.

\section{Introduction}

Methylphenidate is a medication that has been authorised for two indications in France, attention deficit disorder with hyperactivity in children over 6 years (since 1995), and narcolepsy (for Ritaline $^{\circledR} 10 \mathrm{mg}$ ) with or without cataplexy, in cases where modafinil is ineffective, in adults and children over 6 (since 2001). Its known addictive potential, which is linked to its dopaminergic action, documented by both animal and clinical studies, ${ }^{[1,2]}$ has in France led to its classification as a psychoactive drug, dispensed via secure prescription for a limited period of 28 days. It is also subject to a once-yearly hospital prescription (restricted to specialists and departments of neurology, paediatrics, psychiatry and sleep centres). ${ }^{[3]}$ This initial prescription can be renewed by a generalist practitionner, and since April 2008 all prescriptions have been required to carry the name of the issuing pharmacy.

Despite the strict conditions for prescription and issue, the substance is nevertheless associated with a risk in terms of misuse, because of its pharmacokinetic and pharmacodynamic properties, and also its real-world past history, when it was marketed in other countries such as the USA in the 1950s. ${ }^{[1,4]}$

\section{From the emergence of the signal to taking action}

In September 2010, the Provence-Alpes-Côte-d'Azur (PACA)-Corsica CEIP (Addictovigilance Centre) received several notifications from facilities in Marseille specialised in the care of 


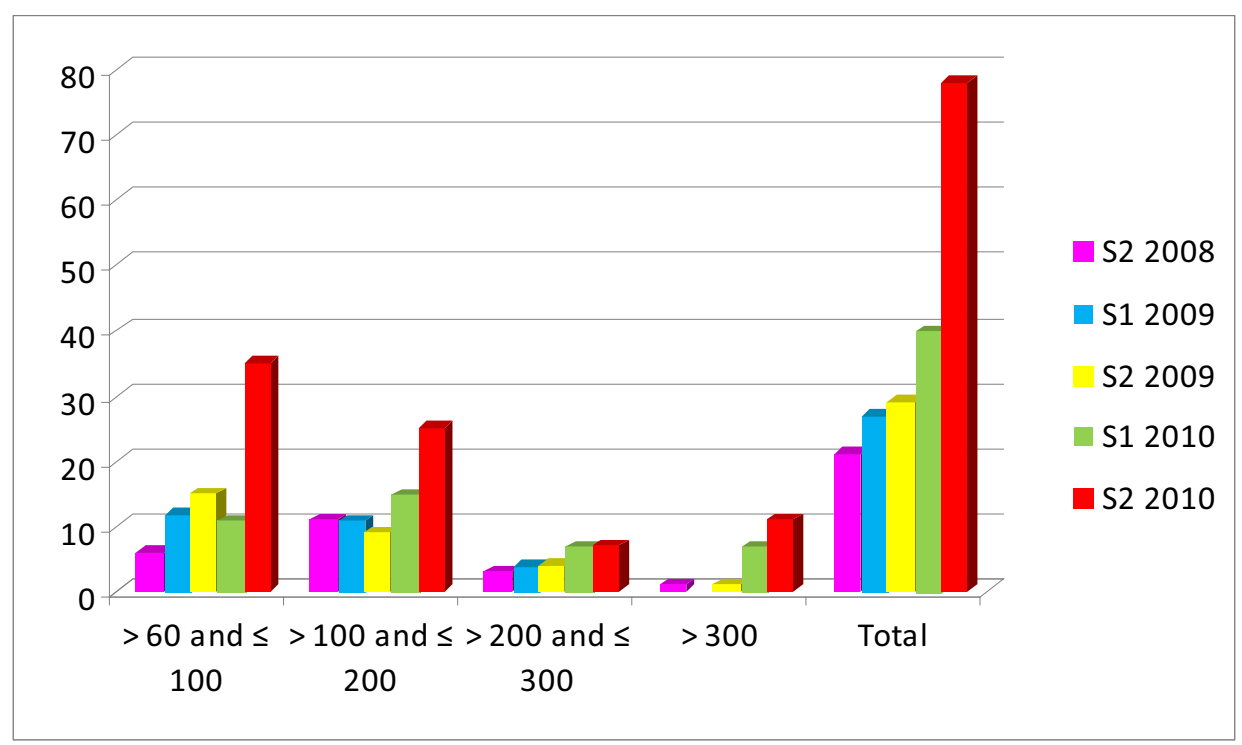

Fig. 1. Semestrial evolution of the number of recipients with a mean dose of methylphenidate (all galenical forms) over $60 \mathrm{mg} /$ day with three or more prescribers (from PACA-Corsica health insurance database 2008-2010).

addicted patients (addiction care and prevention centres [Centre de Soins d'Accompagnement et de Prévention en Addictologie, CSAPA] and drug-user risk reduction center [Centre d'Accueil et d'Accompagnement à la Réduction de Risques pour Usagers de Drogues, CAARUD]) of cases of misuse and abuse of methylphenidate. This information aroused interest all the more because until then this substance had not drawn particular attention in France. The only data available concerned a few cases in the Paris area in 2003 (a communication on seven cases of abuse at the workshop of Pharmacodependance in Biarritz in 2003 by Djezzar et al. CEIP Addictovigilance, Paris). A study conducted in 2010 on data from the PACA-Corsica national health insurance system for the period 2005-2008 evidenced a "deviant" patient profile for methylphenidate use (older patients, 35 years on average, often consumers of other medication such as benzodiazepines, opiate substitution or neuroleptics, with a large number of prescriptions for large quantities of methylphenidate, from different pharmacies and prescribers. ${ }^{[5]}$ On national scale, methylphenidate was also recorded as being on the increase in suspicious prescriptions indicating possible abuse data (ordonnances suspectes indicateurs d'abus possible, OSIAP), and it also appeared in the observatory of illegal or misused psychoactive medications- observatory of illegal or misused psychoactive medications- (observation des produits psychotropes illicites ou détournées de leur utilisation médicamenteuse, OPPIDUM) survey from 2008, with 15 patients reporting that they used it. ${ }^{[6]}$

So as to study what amounted to a "signal" in the region in September 2010 in greater detail, and to describe its qualitative and quantitative characteristics, a large survey was launched (comprising a health section and a pharmacoepidemiological section), based on existing collaboration with agents involved (facilities specialised in addiction, pharmacists, the health insurance body). A cross-sectional study conducted in 2011 in PACA-Corsica region with 64 methylphenidate users (mainly in Nice and Marseille) showed that usage was mainly by intravenous route (for more than $80 \%$ ), using the in immediate-release form of methylphenidate, at average doses of $600 \mathrm{mg} /$ day, with serious consequences on health (insomnia, considerable weight loss, depression hallucinations, cardiac problems, abscesses etc) and major difficulties in providing for their care. ${ }^{[7]}$ Alongside, a study carried out with pharmacies in the region showed that rules for prescription and issue were complied with in only two thirds of cases. A retrospective analysis for the period 2005-2011 on the health insurance database for the PACA-Corsica region showed that the "doctor shopping" indicator rose from $2.4 \%$ to $6.4 \%$. This means that in 2011 the quantity of methylphenidate reimbursed by the health system and obtained via simultaneous prescriptions from several physicians amounted to $6.4 \%$ of the total quantity issued. A retrospective analysis of this same data shows a three-fold increase in the number of subjects receiving an issue of methylphenidate (from 640 to 1877 ), an increase in the proportion of adults subjects (15\% in 2005 against $24.7 \%$ in 2011 ), half of whom were men aged 37.9 on average, and receiving other psychoactive medication $(53.3 \%$ receiving benzodiazepines, $33.6 \%$ antidepressants, $28.1 \%$ medication for opiate dependency, $27 \%$ antipsychotics, $11.8 \%$ morphine, and $2.6 \%$ modafinil). ${ }^{[8]}$

Finally, twice-yearly screening implemented by the PACACorsica health insurance system for patients receiving a mean dose of $60 \mathrm{mg}$ /day or more from three prescribers or more showed that the numbers were increasing, rising from 21 to 78 (figure 1). 
These different pharmacoepidemiological data led to diffusion of information towards all health professionals in the PACA region from CEIP, the Regional Health Authority (Agence Régionale de Santé, ARS), and representatives from the order of physicians and pharmacists, and by way of sensitisation campaigns from the health insurance system and PACA region CEIP. Alongside, all these actions were relayed to the national level via the national addiction vigilance network and the French Drug Agency.

\section{Recent trends of the phenomenon in France (2012-2013)}

In the PACA region, the phenomenon appears to be stabilising, or even decreasing, in particular with respect to the numbers of individuals receiving more than $60 \mathrm{mg} / \mathrm{d}$ with three prescribers or more (falling from 78 in the second semester of 2010 to 44 in the second semester of 2013), and with respect to the number of falsified prescriptions. At national level, data derived from different tools (spontaneous notifications, falsified prescriptions detected by OSIAP, cases reported via OPPIDUM) show that the methylphenidate phenomenon (in immediate or extended release forms) is being observed in several other regions in France (Ile de France, Aquitaine, Languedoc-Roussillon, Pays de Loire, Rhone-Alpes).

\section{Methylphenidate: is there a link between accessibility and abuse?}

The issues of prescriptions of methylphenidate have also increased across the French territory. In a report by French Medicines Agency (Agence Nationale de Sécurité des Médicaments et des produits de santé, ANSM), the national medication safety authority, reporting on the use and safety of methylphenidate, data on sales show that the number of packs sold per year increased from 26000 in 1996 to 220000 in 2005 and 494000 in 2012. ${ }^{[9]}$ An estimate of the number of patients treated, from the "EGB" $\left(1 / 97^{\text {th }}\right.$ representative random sample of subjects from the National Health Insurance System database, which covers all the French population), showed an increase from 25000 in 2005 to 42000 in 2011. Data published in different European countries (Finland, Iceland, Denmark, Norway, Sweden, Spain and Germany) exhibit the same trend. ${ }^{[10-13]}$

A study detailing the OSIAP data on falsified prescriptions on European level showed that methylphenidate had the highest rates of falsification in Spain and Belgium. ${ }^{[14]}$ Cases of methylphenidate abuse have been reported in Switzerland ${ }^{[15-17]}$ and Iceland, where patients had a similar profile to that observed in the PACA region in France: a population using intravenous injection, polysubstance abusers and in a precarious socio-economic situation $^{[18]}$. Interestingly, in these two countries, access to the substance increased considerably, Iceland having the highest level of exposure per inhabitant in the world with 14.4 defined daily doses for 1000 inhabitants per day (ddd/1000 inhab/d). ${ }^{[19]}$ Several authors have suggested that increasing use could be signalling possible diversion. ${ }^{[20-23]}$ To test this hypothesis we compared the evolution of methylphenidate on European scale, and we sought to determine whether the evolution was linked to the appearance of an abuse signal in Europe. ${ }^{[24]}$ Despite the fact that levels of consumption are very varied across Europe, consumption data showed a very marked increase between 2002 and 2010, with an accentuation of the slope in 2004. From 2002 to 2010 the increase in consumption reached $+425 \%$ in Denmark ( 0.8 to $4.2 \mathrm{ddd} / 1000$ inhab/d), $+67 \%$ in France $(0.18$ to $0.3 \mathrm{ddd} / 1000$ inhab/d), $+116 \%$ in Germany (1 to $2.16 \mathrm{ddd} / 1000$ inhab/d), and $+122 \%$ in the Netherlands ( 2.04 to $4.53 \mathrm{ddd} / 1000 \mathrm{inhab} / \mathrm{d}$ ) [figure 2]. The analysis of cases of abuse (mainly involving adult males) from the data recorded in the World Health Organisatoin (WHO) pharmacovigilance collaborating centre, Vigibase ${ }^{\mathrm{TM}}$, shows a significant signal from the last semester 2005, confirming our initial hypothesis. [24]

\section{A multi-source investigation for purposes of prevention and information}

This example of an investigation on methylphenidate shows the importance of possessing complementary qualitative and quantitative data on use, abuse and dependency towards psychoactive substances. The integration of all this pharmacological data in a multi-source, teleoanalysis approach is an essential aspect, providing a body of evidence required to establish action. ${ }^{[25]}$ The reactivity in the instatement of the investigation protocol noted here can be attributed to the national addiction vigilance network with its 13 CEIP (regional centres), and their particular links in each region with other agents involved, in particular via the collective dynamic driven by the yearly monitoring programmes such as OPPIDUM, OSIAP or ASOS. ${ }^{[26,27]}$ Reactivity is indeed a quality to be expected of any surveillance system, and in the example presented here, the investigation, combining several arms, was launched, performed, analysed, diffused and followed up by action within less than 12 months after the signal emerged. In this reactivity, the implication of structures specialised in addiction, in particular the CAARUD facilities, should be underlined, further proof of the importance of working together on addiction vigilance. ${ }^{[28]}$ The regional or inter-regional localisation of the CEIP centres is once again shown to be useful and operational, since it enables geographical specificities in the field of addiction to be documented (for instance factors linked to accessibility, volumes of sales, prescribing patterns, dealer networks, cultural and historical factors). ${ }^{[2,30]}$ The regional and inter-regional scale is also a strong point for interacting with the ARS, as in earlier health alerts (heroin+alprazolam overdose in the Ile de France and Midi-Pyrénées regions, cannabis and serious psychiatric disturbances in the Pays 


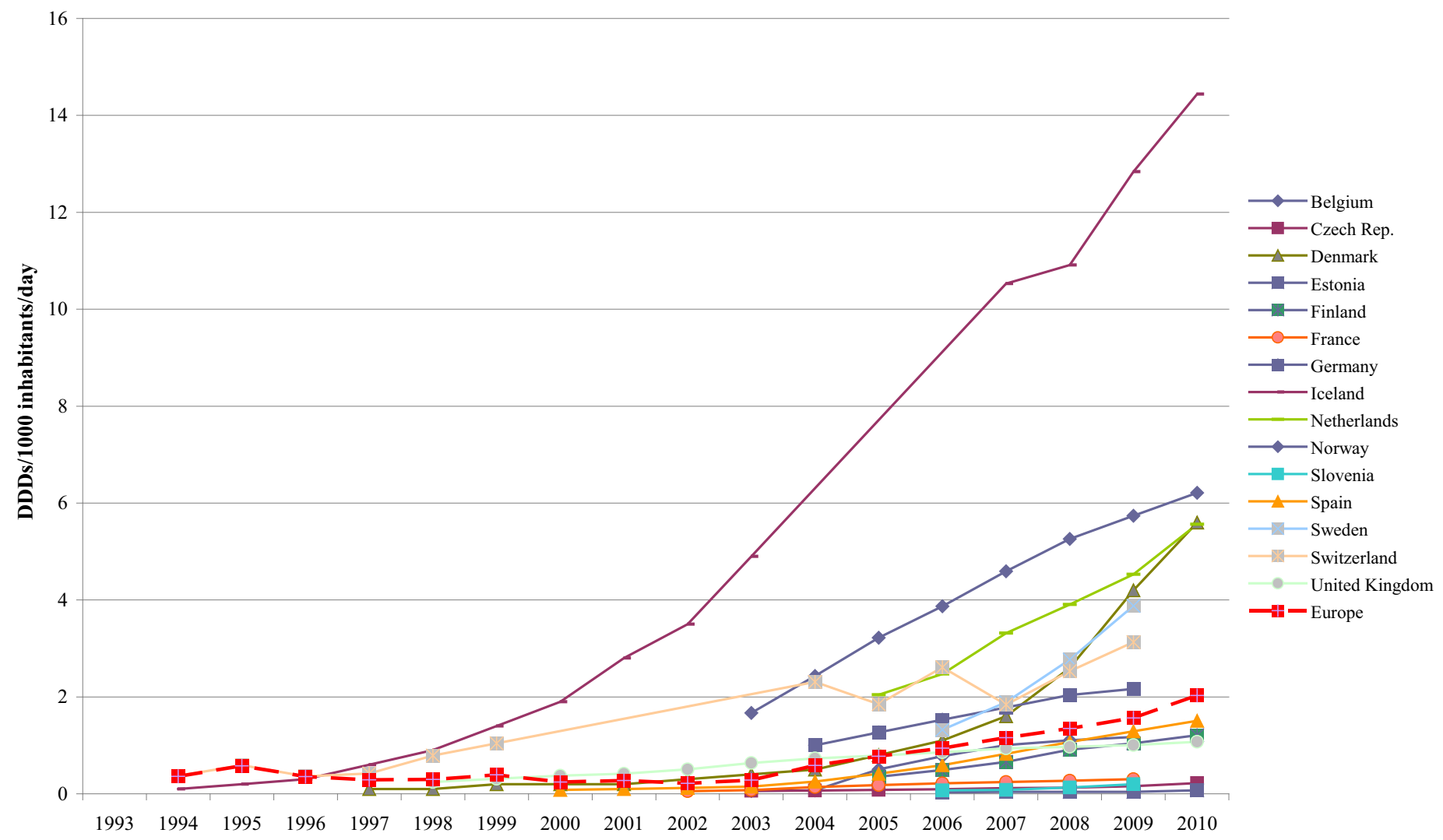

Fig. 2. Evolution of levels of use of methylphenidate*, $\dagger$, for the period 1993-2010, in numbers of daily defined doses per 1000 inhabitants per day (ddd/1000 inhab/d. Source: national statistics $\ddagger$ ).

* Data on the use of methylphenidate is expressed in ddd, not available for Albania, Austria, Bosnia, Cyprus, Hungary, Greece, Ireland, Italy, Lithuania, Luxemburg, Macedonia, Malta, Poland, Portugal, Romania, Slovakia.

†Countries with a level of use $<0.1$ ddd are not included (Bulgaria, Croatia, Latvia, Serbia).

$\ddagger$ Statistics for use derived from national data provided by the different health authorities, except for Switzerland (data from the international drug control body).

de Loire region). ${ }^{[27]}$ The contribution of the health insurance database should also be underlined in documenting the level of medication exposure in the population, the level of misuse from the quantities obtained via "doctor shopping" behaviours, or the characteristics of subjects with "deviant" behaviours. ${ }^{[31]}$ The possibility of integrating a signal into an analysis of exposure and abuse data over time (several years and/or several semesters) is likewise a determining factor for accurate assessment of whether the phenomenon is emerging, all the more important in the area of misuse, where the phenomenon may or may not be a passing craze. The retrospective analysis, using health insurance data on the issue of methylphenidate from 2005 to 2011, also highlighted the fact that the profile of recipients altered over time, with one quarter of the issues involving adults over 35 , a signal in itself, given the indications of this medication in France. This example confirms the conclusions of the 2013 report by Begaud and Costagliola on the importance of gaining knowledge about the use made of medication in real life, which these authors define as being an "essential prerequisite", and the "key to numerous problems".[32] It also shows the value of contextualising any emergent phenomenon, both on national scale, so as to determine whether or not the phenomenon is restricted to a particular territory (the regional specificities mentioned earlier), and on European scale. The data published in other countries has indeed shown that the phenomenon described in the PACA area (on usage, cases of abuse and user profiles) is also described elsewhere, thus strengthening the emergent character of the phenomenon. The particular work carried out by the centre in Uppsala underlines the contribution of the pharmacovigilance databases in the evaluation of the real-life abuse and addiction potential of a substance, as mentioned in a recent study that used the German pharmacovigilance database, ${ }^{[33]}$ and in the most recent report from WHO experts comitee on Drug dependence. ${ }^{[34]}$ Finally, without questioning the therapeutic usefulness of the specialities being prescribed, their use in the more vulnerable populations, such as patients with a history of substance abuse or addictive risk (in particular patients with attention deficit disorder 
with or without hyperactivity), ${ }^{[35,36]}$ should, in the setting described here, be cautious.

\section{Conclusion}

Abuse of and addiction to medication is a major challenge in public health which is evolving fast, in particular in countries such as France, one of the main consumers of medication in Europe. ${ }^{[37]}$ A single source of information is rarely sufficient to measure a phenomenon as difficult to apprehend as addiction to medication. ${ }^{[38]}$ It is indeed important to mobilise all the tools available (in France, surveillance programmes developed by by the French CEIP addiction vigilance network - OSIAP or OPPIDUM, set up by the CEIP centres) alongside data from the health insurance system, and health professional sentinel networks of all types. The latest data available on the abuse of methylphenidate in France suggest a stabilisation in the PACA region, alongside a diffusion to other regions, which requires this information to be relayed as widely as possible, so as to raise awareness of the need to exercise extreme caution in the use of the substance, and to detect misuse in its early stages.

\section{Conflict of interests. None.}

Abbreviations. ANSM: French Medicines Agency (Agence Nationale de Sécurité des Médicaments et des produits de santé); ARS: Regional Health Authority (Agence Régionale de Santé); CAARUD: drug-user risk reduction center (Centre d'Accueil et d'Accompagnement à la Réduction de Risques pour Usagers de Drogues); CEIP: Centre of Evaluation and Information about Pharmacodependence (Centre d'Évaluation et d'Information sur les Pharmacodépendances); CSAPA: addiction care and prevention centres (Centre de soins d'Accompagnement et de Prévention en Addictologie); OPPIDUM: observatory of illegal or misused psychoactive medications (observation des produits psychotropes illicites ou détournés de leur usage médicamenteux); OSIAP: suspicious prescriptions indicating possible abuse data (ordonnances suspectes indicateurs d'abus possibles); PACA: Provence-AlpesCôte d'Azur region; WHO: World Health Organisation.

\section{References}

1. Morton WA, Stockton GG. Methylphenidate abuse and psychiatric side Effects. Prim Care Companion J Clin Psychiatry 2000; 2 (5): 159-64

2. Volkow ND, Swanson JM. Variables that affect the clinical use and abuse of methylphenidate in the treatment of ADHD. Am J Psychiatry 2003, 160(11): 1909-18

3. Frances C, Hoizey G, Millart H, et al. Paediatric methylphenidate (Ritalin) restrictive conditions of prescription in France. Br J Clin Pharmacol 2004; 57: $115-6$

4. Kaye S, Darke S. The diversion and misuse of pharmaceutical stimulants: what do we know and why should we care? Addiction 2012; 107(3): 467-77
5. Frauger E, Pauly V, Natali F, et al. Patterns of methylphenidate use and assessment of its abuse and diversion in two French administrative areas using a proxy of deviant behaviour determined from a reimbursement database: main trends from 2005 to 2008. CNS Drugs 2011 May 1; 25(5): 415-24

6. Frauger E, Moracchini C, Le Boisselier R, et al. OPPIDUM surveillance program: 20 years of information on drug abuse in France. Fundam Clin Pharmacol 2013 Dec; 27(6): 672-82

7. Frauger E, Spadari M, Djezzar S, et al. Étude des pratiques d'injection intraveineuse et autres détournements du méthylphénidate (région Paca-Corse). Le Courrier des addictions 2011; 13: 15-20

8. Ehrhardt C, Boucherie Q, Pauly V, et al. Trends in methylphenidate dispensing from 2005 to 2011. Fundam Clin Pharmacol 2014; 28 (Suppl 1): 21 (A093)

9. Agence Nationale de Sécurité du Médicament et des produits de santé (ANSM). Méthylphénidate : données d'utilisation et de sécurité d'emploi en France. Juillet 2013

http://ansm.sante.fr/var/ansm_site/storage/original/application/ 8dd1277a3867155547b4dce58fc0db00.pdf Accessed December $24^{\text {th }}, 2014$ (26 pages)

10. Treceño C, Martín Arias LH, Sáinz M, et al. Trends in the consumption of attention deficit hyperactivity disorder medications in Castilla y León (Spain): changes in the consumption pattern following the introduction of extended release methylphenidate. Pharmacoepidemiol Drug Saf 2012 Apr; 21(4): 435-41

11. Trip AM, Visser ST, Kalverdijk LJ, et al. Large increase of the use of psychostimulants among youth in the Netherlands between 1996 and 2006. Br J Clin Pharmacol 2009 Apr; 67(4): 466-8

12. Zoëga H, Furu K, Halldórsson M, et al. Use of ADHD drugs in the Nordic countries: a population-based comparison study. Acta Psychiatr Scand 2011 May; 123(5): 360-7

13. Pottegård A, Bjerregaard BK, Glintborg D, et al. The use of medication against attention deficit/hyperactivity disorder in Denmark: a drug use study from a patient perspective. Eur J Clin Pharmacol 2013 Mar; 69(3): 589-98

14. Lapeyre-Mestre M, Gony M, Carvajal A, et al. A European community pharmacy-based survey to investigate patterns of prescription fraud through identification of falsified prescriptions. Eur Addict Res 2014; 20(4): 174-82

15. Bruggisser M, Ceschi A, Bodmer M, et al. Retrospective analysis of stimulant abuse cases reported to the Swiss Toxicological Information Centre during 1997-2009. Swiss Med Wkly 2010; 140: w13115

16. Bruggisser M, Bodmer M, Liechti M. Severe toxicity due to injected but not oral or nasal abuse of methylphenidate tablets. Swiss Med Wkly 2011 Oct 9; 141: w13267

17. Livio F, Rauber-Lüthy C, Biollaz J, et al. Methylphénidate et abus. Paediatrica $2009 ; 20(5): 41-4$

http://www.swiss-paediatrics.org/sites/default/files/paediatrica/vol20/ n5/pdf/41-44.pdf Accessed December $24^{\text {th }}, 2014$ (4 pages)

18. Bjarnadottir GD, Rafnar BO, Sigurdsson E, et al. Methylphenidate use among Icelandic i.v. substance abusers. European Psychiatry 2013; 28 (suppl 1): P703

19. Geirs DP, Pottegård A, Halldórsson M, et al. A nationwide study of ADHD drug use among adults in Iceland 2003-2012. Basic Clin Pharmacol Toxicol 2014 Apr 1, DOI: 10.1111/bcpt.12243

20. McCabe SE, Teter CJ, Boyd CJ. Medical use, illicit use, and diversion of abusable prescription drugs. J Am Coll Health 2006; 54: 269-78

21. Wright ER, Kooreman HE, Greene MS, et al. The iatrogenic epidemic of prescription drug abuse: county-level determinants of opioid availability and abuse. Drug Alcohol Depend 2014 May 1; 138: 209-15

22. Le Lait MC, Martinez EM, Severtson SG, et al. Assessment of prescription opioid intentional exposures across the rural-urban continuum in the United States using both population and drug availability rates. Pharmacoepidemiol Drug Saf 2014 Dec; 23(12): 1334-7 
23. Swanson JM, Volkow ND. Increasing use of stimulants warns of potential abuse. Nature 2008; 453(7195): 586

24. Micallef J, Star K, Palmaro A, et al.. Detection and magnitude of methylphenidate abuse and misuse using vigibase and correlation with level of use in Europe [poster, abstract]. Pharmacoepidemiol Drug Saf 2012; 21: 450

25. Lapeyre-Mestre M, Sapède C, Moore N, et al. Pharmacoepidemiology studies: what levels of evidence and how can they be reached? Therapie 2013; 68(4): 241-52

26. Micaleff J, Jolliet P, Victorri-Vigneau C, et al. First meeting of the French CEIP (Centres d'Evaluation et d'Information sur la Pharmacodépendance). Assessment of the abuse and pharmacodependence potential during drug development. Therapie 2008; 63(1): 55-65

27. Daveluy A, Thirion X. Vigilance sanitaire et agences régionales de santé : quelle évaluation régionale du risque d'abus et d'abus et d'addiction aux stupéfiants et aux psychotropes ? La Lettre du Pharmacologue 2011; 25(2): 57-61

28. Moracchini C, Frauger E, Pauly V, et al. Harm reduction centers ("CAARUD”): privileged places for warning signal detection in addictovigilance. Therapie 2012; 67(5): 437-45

29. Nordmann S, Pradel V, Lapeyre-Mestre M, et al. Doctor shopping reveals geographical variations in opioid abuse. Pain Physician 2013 Jan; 16(1): 89-100

30. Brownstein JS, Green TC, Cassidy TA, et al. Geographic information systems and pharmacoepidemiology: using spatial cluster detection to monitor local patterns of prescription opioid abuse. Pharmacoepidemiol Drug Saf 2010 Jun; 19(6): 627-37

31. Micallef J, Pradel V, Thirion X, et al. Use of the health insurance database by the centres for evaluation and information on pharmacodependance: examples, interests and future prospects. Therapie 2004 Nov-Dec; 59(6): $581-8$
32. Begaud B, Costagliola D. Rapport sur la surveillance et la promotion du bon usage du médicament. Rapport Ministère des Affaires Sociales et de la Santé, 2013 http://www.sante.gouv.fr/IMG/pdf/Rapport_Begaud_Costagliola.pdf Accessed December $24^{\text {th }}, 2014$ (54 pages)

33. Gahr M, Freudenmann RW, Hiemke C, et al. Abuse of methylphenidate in Germany: data from spontaneous reports of adverse drug reactions. Psychiatry Res 2014 Jan 30; 215(1): 252-4

34. Organisation Mondiale de la Santé. Comité OMS d'experts de la pharmacodépendance. Série de rapports techniques 973. Trente-cinquième rapport, 2012 http://apps.who.int/iris/bitstream/10665/78615/1/WHO_TRS_973_fre.pdf Accessed December $24^{\text {th }}, 2014$ (39 pages)

35. Karlstad O, Furu K, Skurtveit S, et al. Prescribing of drugs for attentiondeficit hyperactivity disorder in opioid maintenance treatment patients in Norway. Eur Addict Res 2013, 20(2): 59-65

36. Pérez de Los Cobos J, Siñol N, Pérez V, et al. Pharmacological and clinical dilemmas of prescribing in co-morbid adult attention-deficit/hyperactivity disorder and addiction. Br J Clin Pharmacol 2014; 77(2): 337-56

37. INSERM. Expertises collectives. Medicaments psychotropes. Consommations et pharmacodépendances. 2012

http://www.inserm.fr/content/download/62753/417059/file/Medicamentspsychotropes-fascicule-corpus.pdf Accessed December $24^{\text {th }}, 2014$ (118 pages)

38. Lapeyre Mestre M. Addiction médicamenteuse : quelles données pour évaluer et prévenir? Psychotropes 2013; 19: 65-80

Correspondence and offprints: Joelle Micallef, CEIP-Addictovigilance Paca Corse, Service de Pharmacologie Clinique et Pharmacovigilance, CHU Timone, 13385 Marseille, France.

E-mail: joelle.micallef@ap-hm.fr 